\title{
Cultural Tradition of School Excursion and Collective Trauma of the Motor Vessel Sewol Accident
}

\author{
Hanson Park ${ }^{1,2}$ and Jungwon $\mathrm{Choi}^{3 凶}$ \\ ${ }^{1}$ Department of Anthropology, College of Social Science, Seoul National University, Seoul, Republic of Korea \\ ${ }^{2}$ Institute of Cross-Cultural Studies, Seoul National University, Seoul, Republic of Korea \\ ${ }^{3}$ Department of Child and Adolescent Psychiatry, National Center for Mental Health, Seoul, Republic of Korea
}

The Motor Vessel Sewol accident was a horrible accident, and it had complex ripple effects in various areas such as politics, economy, and culture. In particular, the psychological impact of each individual in Korean society was great, and various explanations for the causes of such psychological mass trauma would be possible. One of these important causes is the historical memory about common cultural custom. Therefore, the historical and cultural memory of the school trips shared by members of Korean society may be one of the causes of the psychological trauma. This paper aims to explain the cultural and social functions of school trips in East Asian societies from a historical point of view. In addition, we will also analyse the reasons why shared cultural memories contributed to the formation of collective trauma of the accident from a cultural, anthropological and psychiatric point of view.

Psychiatry Investig 2019;16(4):256-261

Key Words School excursion, The Motor Vessel Sewol accident, Trauma, Post-Traumatic Stress Disorder, Korean culture.

\section{INTRODUCTION}

In 2014, the large ferry named 'Sewol' was wrecked in the Yellow Sea of Korea. The ship was heading to the Jeju Islands from Incheon. The ship was carrying 476 people, 325 of whom were students of Danwon High School who were on a school excursion. In total, 300 passengers and crew died and only 75 of the 325 students were rescued.

After the catastrophe, profound qualitative changes were generally observed in the lives of those affected. Many people became depressed, nervous and anxious. These bereavements have been aggravated on every anniversary of the catastrophe. However, compared to the number of motor vehicle deaths reported in Korea in 2014 (4,762), the number of deaths of the MV Sewol accident (300) is relatively small. Nevertheless, the total impact of the Sewol disaster on society has been extremely significant and is not limited to the first or second victims. The entire country suffered from the serious trauma.

What is the essential difference between this and other hu-

Received: November 25, 2018 Accepted: January 31, 2019

$\triangle$ Correspondence: Jungwon Choi, MD

Department of Child and Adolescent Psychiatry, National Center for Mental Health, 127 Yongmasan-ro, Gwangjin-gu, Seoul 04933, Republic of Korea Tel: +82-2-2204-0153, Fax: +82-2-2204-0394, E-mail: alzza55@gmail.com

(a) This is an Open Access article distributed under the terms of the Creative Commons Attribution Non-Commercial License (https://creativecommons.org/licenses/by$\mathrm{nc} / 4.0$ ) which permits unrestricted non-commercial use, distribution, and reproduction in any medium, provided the original work is properly cited. man accidents? There may be a variety of cultural interpretations, but I think the relevance of the collective memory of the school trip has played a major role. This tragedy has changed the personal and collective attitudes towards the school excursion, and the significance the significance of their lives as members of Korean society. To understand the cultural deep impact of the disaster, we, first, need to consider the history of school excursions in East Asian countries.

\section{SCHOOL EXCURSIONS IN EASTERN ASIAN CULTURES}

The school excursion (or Shugaku Ryoko in Japanese, Suhak Yeohaeng in Korean) is one of many necessary educational activities, according to teachers and tour guides. The types of school excursions vary from one-day trips to expeditions lasting for several weeks, although they are usually 3 or 4-day trips. Most middle and high schools organize annual educational trips to historical, cultural or natural sites. The trips usually include a variety of group activities such as festivals, athletic sports or talent shows.

Today, hundreds of students can frequently be seen guided by teachers in old cities such as Kyoto, Narai, Gyeongju, or Tainan in the spring or sometimes in the autumn. At high school, excursions are generally allocated for second-year students $(95.3 \%)$ because third-year students need to spend 
more time on studying for the entrance exam, according to a survey by the Japan School Tours Association. ${ }^{1}$ Many people remember their school excursions as the most important school activities, along with school festivals.

Several anthropological studies have been carried out on the function of school trips as a social practice. ${ }^{1}$ For a long time, it has been the first trip a child takes with other people outside the family, such as teachers and other students. They reveal that it is quite useful to investigate social perceptions about the school excursion. Moreover, investigating such social perceptions might elucidate the difference in social practices between relational societies such as Asian countries and individualistic societies like western countries.

\section{HISTORY OF GROUP TOUR IN EAST ASIA}

About one hundred years ago, modern educational system began in East Asian countries (Japan, Korea, and Taiwan). Traditional society did not have a state-dominated general educational system for the public. Educational opportunities were only available for the wealthy and nobly born people; records on regular school trips or other excursions thus do not exist. In other words, school excursions in the East might have begun after the introduction of the modern system of education.

Actually, any record of the tradition of school tours during the Edo period or Jo Seon period has not been found. In Japan, the Diamyo (大名) would regularly reside in the Edo (江户, Tokyo) to accompany his son who would be sent there upon the demand of the Shogun. When the son moved to the Edo, thousands of entourage members accompanied him. ${ }^{2}$ To support them, various accommodations such as the Ryokan or travelling path were developed. In contrast, Korea was a highly centralized kingdom, whereby the king regularly sent government officials to the local provinces in order to govern the regions. Official guesthouses and lodges were constructed for the officials across the country. However, personal tours for leisure were very rare. Although some noblemen of the privileged class consider the visiting of holy mountains or shrines as a rite of passage, these were exceptional cases. ${ }^{3}$

After the 19th century, the general public gradually began to take tours, similar to the modern practice. Basically, tours in Asian countries can be divided into two categories: individual arranged trip (Tehai Ryoko, 手配旅行) and group package tours (Shusai Ryoko). The latter is more popular in Korea and Japan, primarily because of the convenience and affordability. However, the real reason for the preference for Shusai Ryoko is peoples' strong anxiety about independent travelling in unfamiliar places. ${ }^{4}$ Paradoxically, participants of package tours may feel a strong sense of belonging with other participants during the tour, even though they may never have met each other before the trip. Often, their group relationship is maintained by farewell parties or even by arranging further tours as companions.

\section{BEGINNING OF SCHOOL EXCURSION}

In 1886, the first school excursion was introduced at the Tokyo Normal School. The principal, Takamine Hideo, was influenced by the Western practice of school excursions while studying in New York. Upon his return, he first organized a field trip for the subjects of geography and science. In later years, the school trip was rapidly adopted by other senior schools; however, the nature of school trips has since considerably changed. ${ }^{2}$

After the victory of the Russo-Japanese War, the number of tours to Manchuria significantly increased. Interestingly, the Japanese Army (Rikugun) supported the transportation and medical aid of students. The army sent officers to help in the school excursions in which students were made to march as a group similar to troops. Students were divided into two large groups, and then into six small groups. A leader was appointed to control each small group. The leader commanded the gathering and movement of his group. Major tour sites included the renowned battle zones of the Russo-Japanese war or industrial facilities. Army officers presented lectures on the spirit of militarism as being sacred for the nation. ${ }^{4}$

Because the school excursion was the extension of the educational training system of laborers and soldiers for the nation and the emperor, an excursion for girls did not exist until the 1930s. After the Tokyo girls' schools had established school trips, excursions for cultural purposes were slowly adopted in girls' schools. ${ }^{2}$ Unfortunately, these very small changes were interrupted with the beginning of the Pacific War.

After World War II, common places for school excursions became cultural or traditional cities which could be accessed by trains, such as Tokyo, Kyoto or Narai in Japan and Seoul, Gyeong ju or Gong ju in Korea and Tainan in Taiwan. Students in big cities such as Seoul tended to visit local cities, while students in local provinces tended to visit big cities. Recently, the destinations of school trips have become broadened to Hokkaido, Okinawa, Jeju Island or even more distant countries such as Europe or the US.

\section{PERCEPTION ABOUT THE MEANING OF THE SCHOOL EXCURSION: EAST AND WEST}

The school excursion is considered to be a very important aspect of school life. According to a previous study, a teacher has been reported as stating the following. ${ }^{1}$ 
'Whenever I join the reunion party of senior school, I and my friends have always talked about the memories of school excursion after the short exchanges of recent lives of each other'.

As reported by the Japanese School Tour Association, the most important aim of school excursions of a senior school is 'getting the good experiences about group life's etiquette and public moral (61.2\%)'. The second significant purpose, perceived by the teacher respondents, is 'strengthening mutual relationships with teachers and other students (57.9\%)'. Other aims such as 'awareness of nature's beauty', 'getting school memories', 'seeing local culture and lives' or 'studying geography, history, politics, economics directly' are regarded as less important, at $45.4 \%, 45.2 \%, 39.1 \%$, and $37.5 \%$, respectively. ${ }^{1}$

The Korean Educational Tour Association describes the purpose of school excursions as follows. First, their role is for the students to explore cultural, economic, industrial, and political places and to thereby enrich their insight and appreciation for other cultures. Second, they provide desirable learning experiences about public health and safety, customs of other groups' lives, and public morals. Third, they enable rich memories with teachers and classmates while discovering other worlds. In summary, school excursions of eastern countries, especially those in Japan and Korea, are focused on teaching basic relational customs to become enlightened members of society (Shakaijin, 社会人).

However, attitudes toward school excursions in Western societies appear to slightly differ to those in Eastern societies. The primary purpose of school excursions is mainly as a field trip for science, art, and cultural experience. The major benefits of the field trip suggested in Western literature are as follows: to provide firsthand experience, to stimulate interest and motivation, to add relevance to learnings and interrelationships, to strengthen observation and perception skills, and to promote personal and social development. ${ }^{5}$ According to another study, school excursions have 10 desirable effects, including only one that suggests interpersonal relationships, 'provide opportunities and encouragement for students to engage in discussion with adults (teacher, chaperones, museum staff) and with other students. ${ }^{6}$

Very few studies have been performed on teachers' perceptions about the school excursion in western societies. However, we can assume individualistic attitudes through one Australian case study about school excursion planning and constraints. The authors present 20 motivations related to school excursions, such as attractions with educational merit (4.7 in 5-point Likert scale), cost-effective attractions (4.6), and relevance to studies (4.6) and so on. Only one attribute is related to student bonding (4.3). Generally, school excursions in Western schools are only aimed at enriching individual experiences and knowledge related to science, history, art, and geography. ${ }^{7}$ Awareness of public moral or good memories with teachers or friends can be expected, but these are subsidiary and incidental.

\section{SCHOOL EXCURSION AS A RITE OF PASSAGE}

Western and Eastern societies have a long tradition of youthoriented trips. People of the privileged classes customarily spend several years travelling countries such as England, Netherlands, France and Italy via the Alps as they consider this builds healthy characteristics and good knowledge of the cultural legacy of the Classics and the Renaissance. ${ }^{8}$ Similarly, visiting the traditional Confucian sites in Korea or making a pilgrimage to Shinto shrines in Japan has traditionally been highly recommended for the sons of nobility, as mentioned earlier., ${ }^{2,3}$

However, the basic concept of current school excursions in Asian countries differs somewhat from the tradition of the privileged class' Grand Tour. In the spring, numerous school excursions are performed on a national scale in Japan, Korea, and Taiwan. More than 95\% of students participate in the excursion. Participation is almost mandatory. Thousands of charted buses, special trains, ships, and planes carry a large number of students every year at special excursion rates. ${ }^{4}$

During the entire excursion period, all students are expected to obey the rules of the trip and commands of the teachers. Sometimes, specialized instructors take over the teachers' management of the students. They are often divided into small groups with a leader, and the leader then controls their groups. Students need to quickly adapt to the new rules and the new orders. Individual activities are strictly banned. If a member deviates from the rule, all members of the group are punished. Commonly, they attend group performances such as group dances, chorus or short comedy on the last night of the trip in the auditorium. Strong solidarity is the most important rating criteria, whereby each member must sacrifice himself or herself for the benefit of the group, and the pride of his or her school.

However, this over-inflated community spirit can lead to unwanted outcomes. Encounters with other school excursion groups are not uncommon, because most high schools carry out excursions during the same period at several of the same places. The threat of a group leaving the excursion occasionally occurs. While fighting among groups accompanied with serious physical assaults is extremely uncommon, most high schools boast legends of previous students' glorious and bloody battles, the truth of which remains uncertain. 


\section{COLLECTIVE EXPERIENCES AS A CULTURAL PHYLOGENY}

In East Asian countries, the school excursion 'Shugaku Ryoko or Suhak Yeohaeng (修學旅行)' refers to a culture-specific social rite of being a social member. It functions as a ritual process of socialization, of being intact 'Shakaijin or Shheoin (社會人).'2 All students are expected to obey the rules of the trip and the commands of teachers. Every individual student must sacrifice himself or herself for the triumph of their group, and the pride of their school. After the sacrifice of individuality, they can be a respectable social member of the community. This constitutes a type of implicit promise between the new and old generations. Young people must express their respect of the traditional order of the organization. Teachers represent older people who are committed to the educational development of younger people, and admit them as members of societies. $^{4}$

Similarly, school excursions in East Asia have been seen as the last continuum of socialization as a rite. In brief, the tradition of school excursions in Japan, Korea, and Taiwan has evolved as a branch of the phylogenetic tree of a broader cultural stem for the past 100 years. ${ }^{1}$ The characteristics of school excursions are listed in Table 1 as follows.

Two days after the Sewol accident, the vice-principal of the school committed suicide by hanging himself in front of the seaport where the students lost their lives. The major reason for his suicide was based on ethics, as shown in his suicide note:

'The plan of school excursion was my idea. It is all my fault entirely. I do not deserve to survive without knowing where my students are now. I hope I could be a teacher for them on the other side, in death. Please, scatter my ashes where my students are missing.
In fact, maintaining students' safety is not the responsibility of the vice-head. However, he considered himself to be a surrogate of the pre-existing society. ${ }^{9}$ When students promise to obey the social rules, society should guarantee their safety. During the wrecking of the Sewol ferry, the captain, crew, and some of the teachers instructed the students to remain in the 'deemed safe' cabins. However, this command proved to be erroneous. Some of the general passengers ignored the request, but most of the students followed the command given by their elders out of a sense of respect. However, for this reason, most of the fatalities were students.

All cultures have their specific ways of caring for others at different stages of life, during crises and under different conditions. ${ }^{10}$ The Sewol MV disaster was a case where the steadfast adherence to tradition have broken. In this context, the vice-principal felt responsible for the students' safety and adhered to the old way of life. Students, teachers, and the affected members of society may have regarded the school excursion as a ritual of social acceptance and recognition in the level of collective unconsciousness.

\section{PERSONAL MEMORIES AS AN INDIVIDUAL ONTOGENY}

After the Sewol MV disaster, a 29-year-old trainee teacher asked for psychiatric help at the Disaster Relief Headquarters set up for the Sewol MV accident. As a psychiatric consultant of the Korean Disaster Mental Health Committee, the author took on the trainee as a client. The client was a temporary teacher at Danwon High School who would have been responsible for teaching the 30 students during the school excursion, 28 of whom perished in the tragedy. By chance, he was unable to attend the excursion. Among the 14 participating teachers, 10 teachers died and 2 were declared missing. The trainee's supervising teacher also died.

The trainee teacher has since been troubled with insomnia,

Table 1. Comparison of school excursions in western and East Asian areas

\begin{tabular}{|c|c|c|c|}
\hline & \multicolumn{2}{|c|}{ Western Europe, or areas influenced by westernized educational system } & \multirow{2}{*}{$\begin{array}{c}\text { East Asia } \\
\text { School excursion in the Contemporary } \\
\text { School in Japan, Korea and Taiwan }\end{array}$} \\
\hline & Grand tour since 16th Century & $\begin{array}{l}\text { School excursion in the Contemporary } \\
\text { Western School }\end{array}$ & \\
\hline Classes & Noble class & All classes & All classes \\
\hline History & During renaissance age & $\begin{array}{l}\text { After establishment of modern } \\
\text { educational system }\end{array}$ & After the meiji restoration \\
\hline Regions & Western Europe & Western Countries & East Asian Countries \\
\hline Main purposes & Individuation as a rite of passage & Scientific or cultural experience & Socialization as a member of a group \\
\hline Size of group & Alone or a couple of companions & $\begin{array}{l}\text { Varied (Usually } 6 \text { to } 30 \text { students, a group } \\
\text { is recommended) }\end{array}$ & $\begin{array}{l}\text { All students of the school, } \\
\text { usually more than several hundred }\end{array}$ \\
\hline Season & Not specified & Varied & Specific period (usually, spring or autumn) \\
\hline Duration & Several weeks to several years & Varied (from 2 hours to several days) & From 3-4 days to several weeks \\
\hline
\end{tabular}


grief, and anxiety. In the consultation, he could not stop crying. His clinical presentation closely fit the criteria of complicated PTSD. He proceeded to recount his recent feeling and thoughts as follows.

"When I got to the classroom, there were only 28 chrysanthemum on the desks of victims. Personally, I was eager to become a good teacher because I thought teacher is one of the most important occupations. I desire to be a respectable role model for my students. But all of them passed away because of naive obedience to the stupid instruction. They simply stuck to the erroneous emergency announcement like innocent fools. I watched the news about the accident. I could see my colleague teachers on CCTV, they told my students 'Stay still. Don't move'. I had nightmares several times. In the dream, I killed my students. I don't have any confidence in teaching. How can I sure my lessons are right for students? I already lost the most of my students. They all were so good students. I am feeling significant doubts about future as a teacher."

Cultural meanings of a social performance are not confined within each social groups, persons or linguistic terms, but rather co-emerges among all of them. ${ }^{9}$ Without considering the cultural meanings of certain actions, we are unable to address this existential scepticism. While the teacher trainee's diagnosis was PTSD, he was not able to be helped, since various medications and conventional psychotherapy did not seem to assist him.

An individual's world view is closely linked to the collective beliefs about life. The patient's pain not only derived from direct traumatic experiences, but also from his ontogenetic personal history contingent upon his context. He had accumulated personal beliefs for 29 years that were based on a need to belong to a community that respected the role of the teacher in society.

Without considering his role as a 'shakaijin' (a teacher) in this case, his presentation of PTSD would not be understood, given that he fortunately survived the disaster. This was not the only case of survivors' guilt. While facing the type of technological and social disaster as that of the Sewol MV wrecking, people unrelated to the victims express pathologic responses like depression, anxiety and anger-bursting because the disaster is not only a social concern, but also an individual concern. While the people unrelated to the victims and those related to the victims complain of similar PTSD symptoms, the reasons differ between the two types of people. ${ }^{11}$

\section{CONCLUSION}

The educational trip has a long history in both the West and East. However, the social meaning differs somewhat according to the cultures. In Western society, school excursions are conducted mainly for individual development on understanding scientific, cultural or artistic experiences. However, in Eastern society, Shugaku Ryoko may function as a social means to train students as desirable social members. It is unclear whether these differences reflect the collective unconsciousness of each affected person at a deep level or only the recent social consequences of Japanese militarism in terms of particularism. In any case, the practices of school excursions in East Asian countries might reflect the basic frame of relational society and relational psyche.

Individual or collective value of life has a significant impact on our physical, psychological, and societal existence. The actions taken by people in daily life cannot easily be separated from our social culture. Also, shared identity as cultural beings can change; it is not an inevitable outcome, but a result of historical processes. ${ }^{12}$

The Sewol MV accident continues to cause significant trauma for many people. Pain and grief were not restricted to the families of direct victims. It has become an extremely traumatic event for all people who have the same collective memories in the community. The traditional belief about the meaning of life as a 'shakaijin' in society proved to be dominant, and every person doubted their purpose in life as a member of society. Everyone felt that the traditional promise of obeying elders was detrimental. Recovery from trauma has continued, and the scar is deeper and angrier than at the time of the disaster.

Three countries in East Asia have 100 years' history of school excursions, but the social performance of school excursions is rapidly changing as a consequence of these traumatic accidents. Some people mourn the demise of traditional school excursions due to their fond personal memories and belief in their role in the rites of passage of the 'shakaijin'. Perhaps, changing customs has an influence on our society, as it adapts to the changing traditions. The onset of the school excursion as a social ritual was not historically inevitable, and was rather the result of merely a combination of nationalism and collectivism at that time. Culture is destined to be converted from a diachronic view to a synchronic view. Individual lives affect the process of this change and are also affected by the change itself.

From a clinical viewpoint, identifying the cultural meaning of disaster for each victim is essential in formulating effective therapeutic plans. However, culture is not a static set of beliefs. It is continually reconstructed through social processes. ${ }^{13}$ 
In this sense, disaster will be an important factor to add new memories to social performances such as old traditions or customs. For a long time, natural disasters have served as one of the primary motivators of human evolution. Hopefully, our painful experiences through a series of disasters may function as another motivator to extend our ontological awareness.

\section{Conflicts of Interest}

The authors have no potential conflicts of interest to disclose.

\section{REFERENCES}

1. Guichard-Anguis S. Japanese Tourism and Travel Culture. New York: Routledge; 2009.

2. Tatsuo K. A century of school excursions. JPN Quart 1987;34:287-290.

3. Kyujanggak. Joseon Salamui Joseonyeohaeng. Paju: Geulhangari; 2012.

4. Yim S. School excursions to Manchuria in 1930s Japan: focused on the trip network and imperial consciousness. Dongbuga Yeoksa Nonchong 2011:157-188.

5. Behrendt M, Franklin T. A review of research on school field trips and their value in education. Int J Environ Sci Educ 2014;9:235-245

6. DeWitt J, Storksdieck M. A short review of school field trips: key findings from the past and implications for the future. Visitor Stud 2008;
11:181-197.

7. Ritchie BW, Coughlan D. Understanding school excursion planning and constraints: An Australian case study. Tourism Rev Intl 2004;8:113-126.

8. Black J. The British Abroad: the Grand Tour in the Eighteenth Century. Sutton: Stroud; 2003.

9. Crook JH. Shamans. Yogins and Indigenous Psychologies. In: Dunbar RIM, Barrett L, Editors. Oxford Handbook of Evolutionary Psychology. New York: Oxford University Press, 2009, p.519-530.

10. Leininger $M$. Teaching transcultural nursing in undergraduate and graduate programs. J Transcult Nurs 1995;6:10-26.

11. Weisæth L, Ursano R, McCaughey B, Fullerton C. Psychological and Psychiatric Aspects of Technological Disasters. In: Ursano R, McCaughey B, Fullerton C, Raphael B, Editors. Individual and Community Responses to Trauma and Disaster: The Structure of Human Chaos. Cambridge: Cambridge University Press, 1994, p.72-102.

12. Wilson J, Tang C. The Lens of Culture: Theoretical and Conceptual Perspectives in the Assessment of Psychological Trauma and PTSD. In: Wilson J, Tang C, Editors. Cross-Cultural Assessment of Psychological Trauma and PTSD. New York: Springer, 2007, p.3-30.

13. Anderson I, Baum F, Bentley M. Beyond Bandaids: Exploring the underlying social determinants of Aboriginal health. Papers from the social determinants of Aboriginal Health workshop, Adelaide, July 2004. Cooperative Research Centre for Aboriginal Health; 2007. 